\title{
A natureza não é uma palavra vazia
}

\author{
Eliezer Martins Rodrigues ${ }^{1}$
}

DOI: http://dx.doi.org/10.20435/tellus.vi44.724

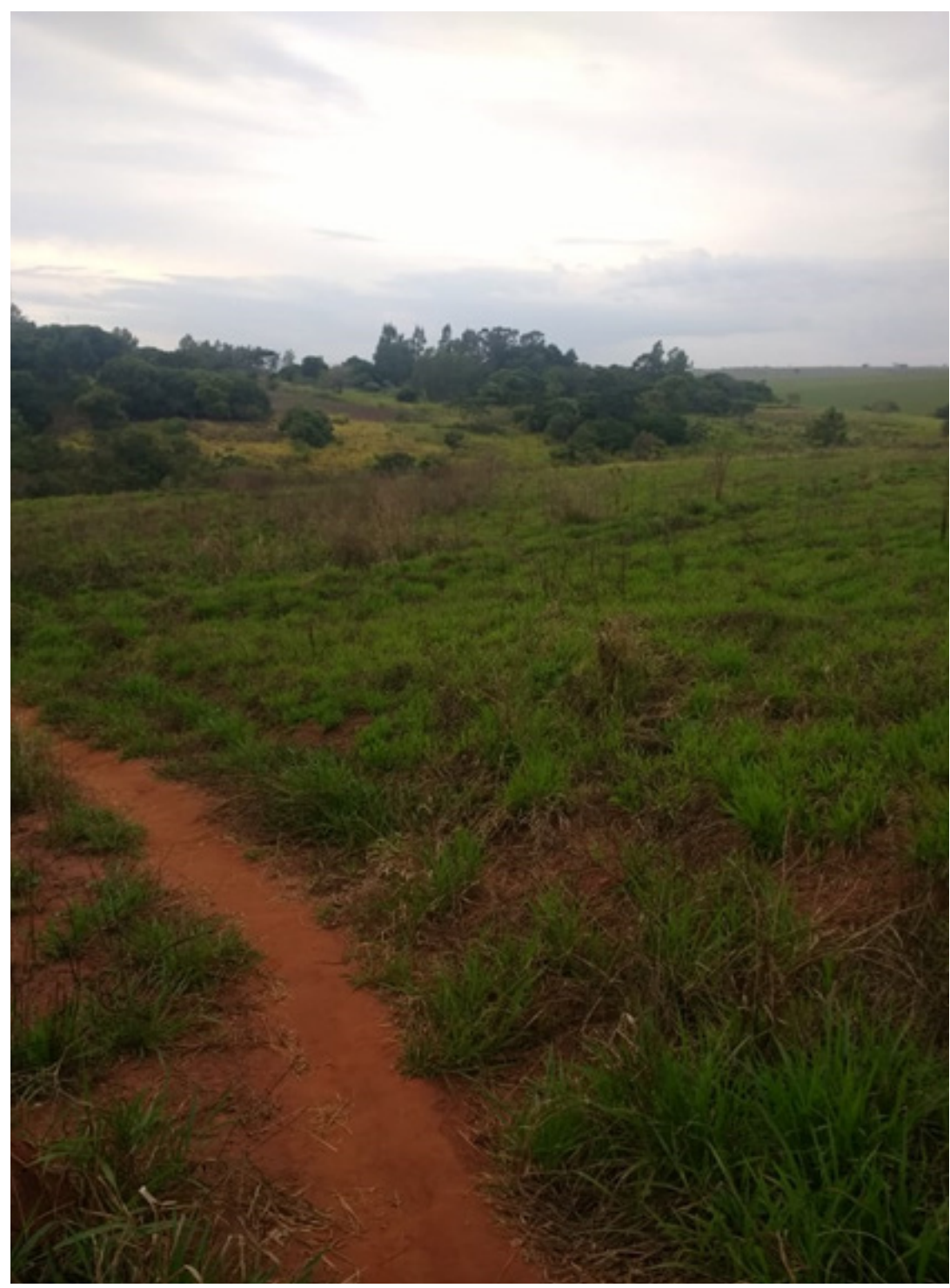

Fonte: Acervo do autor (2020). Porto Lindo (Jakarey) Yvy Katu. 


\section{AS PALAVRAS GUARDADAS}

Eu me chamo Eliezer Martins Rodrigues. Sou índio da etnia Guarani Ñandeva, recebi meu nome indígena como Avá Tendo Tá, que significa sempre em frente aos desafios. Sou pesquisador indígena sobre os conhecimentos do meu povo, fiz minha formação no ensino médio da escola Vilmar Vieira Matos, o magistério em Dourados, Mato Grosso do Sul (MS), sou licenciado em Ciências Sociais pela Universidade da Grande Dourados (UFGD), mestre em Educação pela Universidade Católica Dom Bosco (UCDB), e hoje sou coordenador e professor na minha aldeia, o território Porto Lindo (Jakarey) Yvy Katu, que fica no Sul do Mato Grosso do Sul, na fronteira com o Paraguai. Sou um pesquisador que estou sempre em busca de um mundo equilibrado para o meu povo e para o mundo.

Na cultura Guarani Ñandeva, a visão sobre o mundo hoje como ele se encontra isso é conforme os rezadores e os sábios Guarani nos dizem, que a terra ainda está segurando o nosso planeta por meio da lua e do sol. A lua esfria um pouco e o sol aquece, e assim vai equilibrando o calor da humanidade. Mas, de acordo com os rezadores, a lua não quer mais atender a humanidade, já está querendo deixar os seres humanos e aí corremos um risco muito grande, pois somente o sol sozinho não vai conseguir manter a terra, não vai ser possível produzir nada e isso a humanidade precisa saber, porque precisa da união entre as culturas existentes aqui na terra para saber o que está acontecendo com a terra, o nosso planeta.

A natureza não é uma palavra vazia pra nós os Guarani Ñandeva, porque a natureza nos inspira, por isso que nos indígenas respeitamos a natureza, porque ela é um conjunto de espécies de vida que nosso planeta possui, principalmente a vida dos Guarani. Por isso que a gente fala que a água, os trovões, a lua, o sol, o vento, os pássaros, tudo isso esta ligado na nossa cultura. E esse conhecimento Guarani Ñandeva vai ajudar os outros povos, os não-indígenas, as pessoas da cidade, enfim, o mundo, para que o mundo fique equilibrado.

Aqui na nossa Aldeia Porto Lindo (Jakarey) Yvy Katu estamos construindo uma casa de reza grande, que cabe mil pessoas e iremos inaugurar com reza onde iremos batizar as pessoas, as plantas e a terra em nome de todos os seres humanos, e pediremos ao grande Deus Tupã que o sol não pare de aquecer a humanidade e a lua também não pare de congelar a terra, porque somente assim o mundo vai sempre estar equilibrado. Na cultura Guarani Ñandeva, o sol e a lua são gêmeos 
e eles que mantém o mundo equilibrado para humanidade. Essa escrita você não vai encontrar em nenhum livro no mundo, e eu permito que seja escrito agora.

Por isso na cultura Guarani Ñandeva a palavra natureza não é vazia, dentro da palavra existe o passado, o presente e o futuro, que permanecem nos orientando e se comunicando através da natureza. A natureza para nós Guarani é água, o vento, as matas, os rios, a fumaça do rio, o fogo, a fumaça do fogo, os pássaros, os animais, os cantos dos pássaros, as estrelas, as plantas medicinais, a terra, as cores da terra e as cores do céu.

Nós, os Guarani Ñandeva, durante a reza lembramos dos outros povos que não são indígenas, e que eles nos ajude também, pois afinal, nós lutamos pela defesa do nosso planeta.

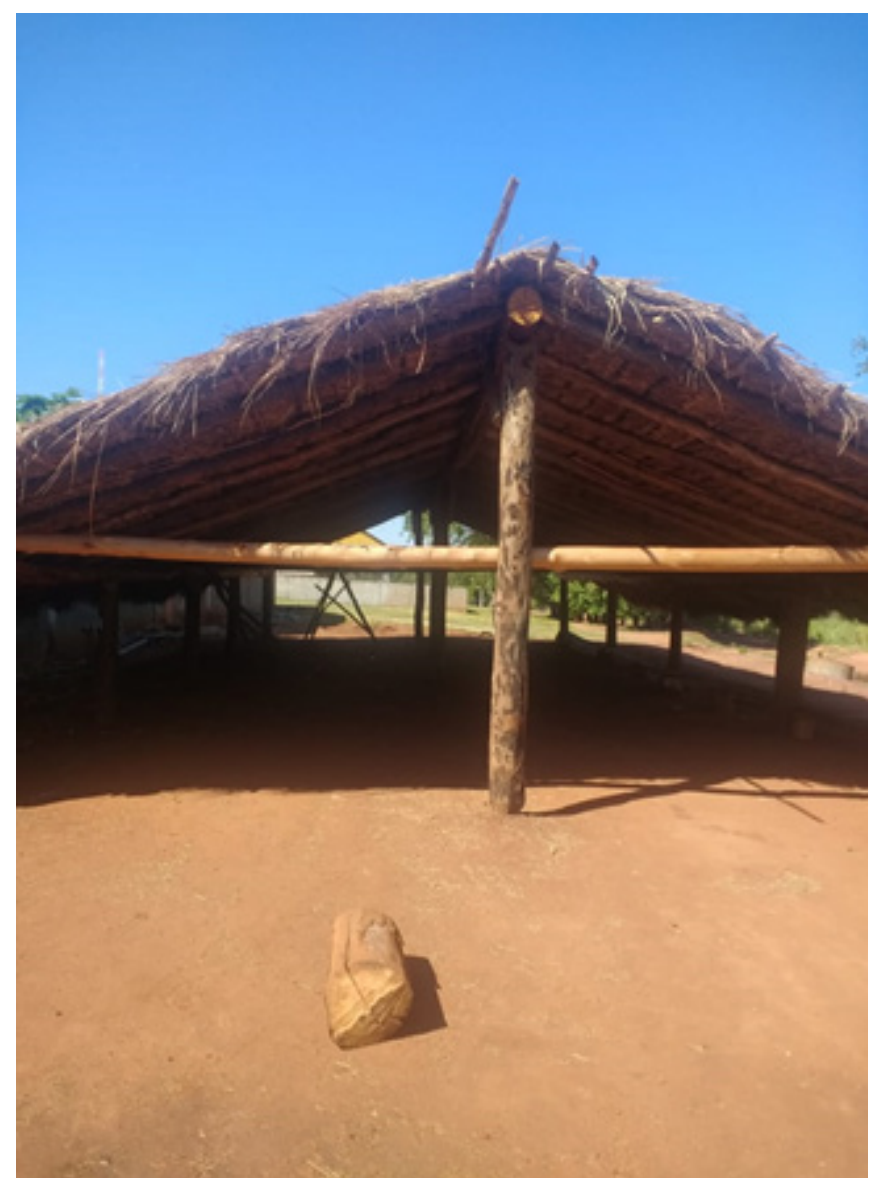

Fonte: Acervo do autor (2020). Porto Lindo (Jakarey) Yvy Katu. 
Então, a natureza não é uma palavra vazia para os Guarani Ñandeva, olha o mato, na floresta tem frutas, mel, animais, pássaros, madeiras, flores, insetos, plantas medicinais que são sagradas para os Guarani Ñandeva, e nós temos rezas para pedir e entrar na floresta, pois na cultura Guarani, a natureza tem seu Jara, o guardião da floresta, aquele que cuida da floresta, que cuida de todas essas plantas que citei acima que são sagradas. Não podemos entrar e destruir a floresta, pois se isso acontecer, pode afetar a nossa vida mais adiante, o Jara, o guardião da floresta, não irá nos perdoar.

Para pegar o pé de Cedro, o rezador/xamã faz uma reza pra depois pegar ou tirar uma casca, e trazer para a casa de reza, e isso acontece somente quando vai ter batismo, esse modo de viver dos Guarani não é de hoje, vem de geração e geração há muitos e muitos anos. Hoje aqui na aldeia cada família planta essa madeira tão importante para os Guarani, o Cedro, pois a natureza serve para gente sobreviver e cuidar das nossas crianças, e serve também para os animais, pois quando a criação tem alguma doença, o rezador/xamã faz uma reza, e dá a água benzida para a criação, para curar os animais. Por essa razão, e muitas outras, a natureza não é uma palavra vazia. A natureza é vida, a vida que Deus criou para os seres humanos cuidar e não destruir.

A natureza não é vazia porque a natureza completa a existência do povo Guarani, a gente se sente completo com a natureza, pois a natureza oferece para nós tudo que é sagrado, na natureza esta a alma e o espírito, enquanto os não-indígenas esperam só o lucro, para nós é diferente, pois quando morre um pé de Cedro, também morre a alma e o espírito, se um dia acabar a natureza, vai acabar a reza. Como os Guarani vão fazer a reza, para que vai servir a reza se acabarem com a natureza, os povos em si vão todos acabar. Os não-indígenas trata a natureza como objeto de lucro, e assim transformando a natureza em objetos, eles usam vários tipos de madeiras que são sagradas para os Guarani. 


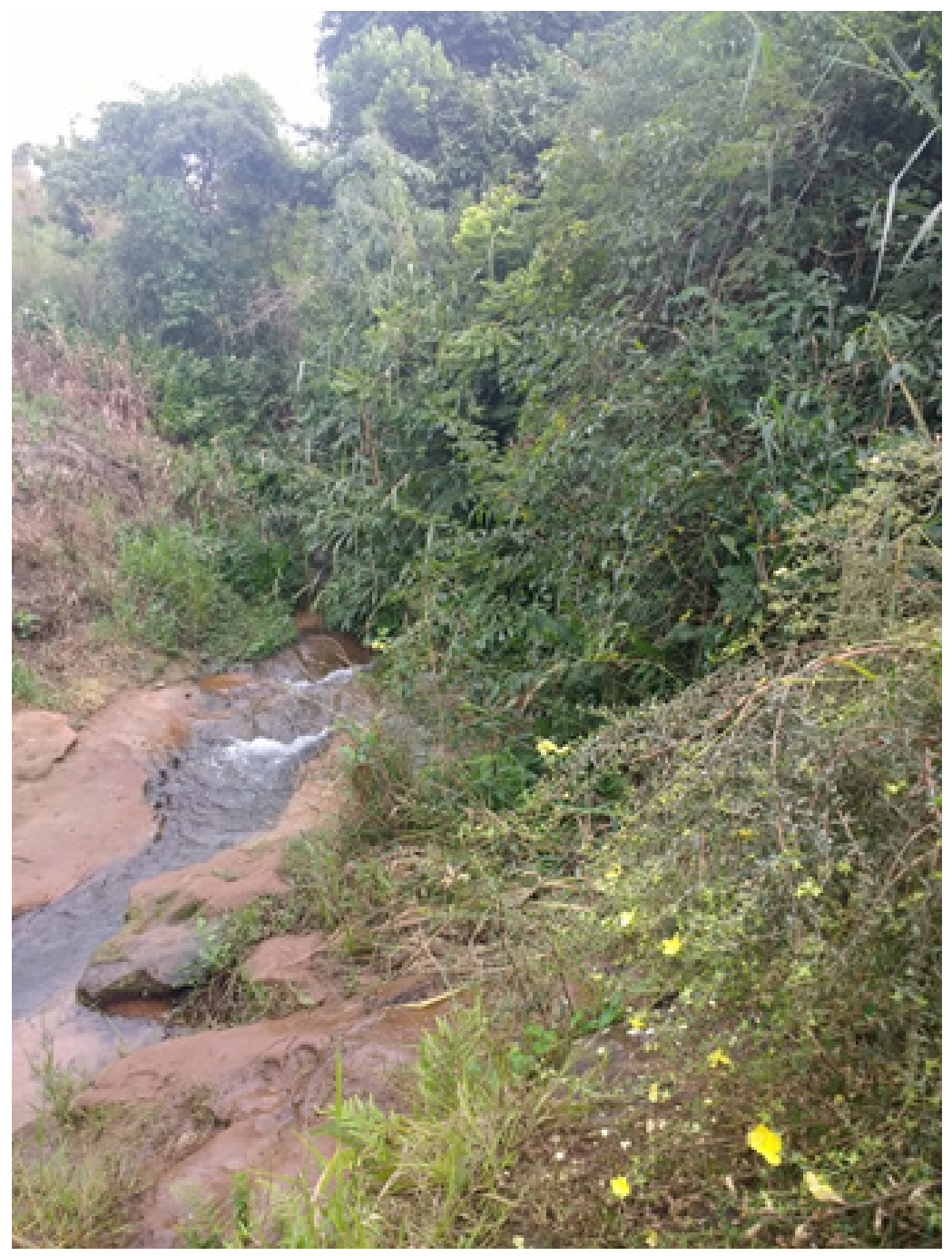

Fonte: Acervo do autor (2020). Porto Lindo (Jakarey) Yvy Katu.

A natureza para os Guarani é tudo, pois nossa subsistência depende da natureza, nela que está a riqueza. A natureza que mantêm nossa cultura, pois da natureza buscamos remédios, frutas, raízes das plantas medicinais, e quando construímos nossa casa, temos reza para fazer, e essa reza precisa da natureza, se não existe as matas como iremos fazer a reza. Então, se a natureza acabar, também acaba as rezas, na nossa cultura temos vários utensílios que usamos que são da natureza. 
Nós acreditamos que a natureza tem os Jára's, que são os guardiões da natureza, que respeitamos, cada Jára tem a sua reza como para as árvores frutíferas e as plantas medicinais, e as árvores que servem para o batismo como o Cedro que é uma madeira que serve para fazermos a cruz para quem faleceu. Tudo isso vem da natureza, e por isso a natureza para os Guarani é sagrada.

A nossa vela é um exemplo, essa forma de uso vem há muitos e muitos anos, eu me lembro da minha mãe falecida quando vejo nossa vela indígena, que é feita de cera de Jataí para o batismo de crianças, e também das plantas e das sementes que plantamos. Por isso a natureza não e uma palavra vazia para os Guarani Ñandeva.

A mata oferece essa continuidade da cera o próprio Jataí. A mata, o Guarani, a reza, as crianças, a reza do batismo, tudo isso é um conjunto de espécies que pertence ao povo Guarani.

O mato tem ligação com a vida dos Guarani, o Jataí precisa do mato assim como os Guarani precisam da cera, e as crianças precisam da água de Cedro. Essa madeira de cedro é tudo para os Guarani, nós fazemos a cruz para o falecido ou a falecida, a casca colocamos na água para o batismo da criança, então a natureza fortalece a cultura, a reza, o batismo e a vida, desde o nascimento até a morte.

A natureza é para nós Guarani, toda nossa riqueza, o nosso natural, não existe outra riqueza para nós, pois este é o nosso corpo completo.

A natureza é um conjunto de terapia pra nós. Ela limpa a alma, refresca o pensamento, abraça o corpo dos guarani, isso porque na natureza nos encontramos plantas medicinais que tomamos no tereré e no chimarrão, também para tomar banho plantas que refresca o corpo adoecido que serve de massagem. Então, a natureza nos oferece tudo isso, mas para manter esses remédios é preciso de muito respeito, saber quais são os cuidados e respeitar os Járas guardiões da natureza que o rezador fala e repassa durante a reza, por isso cada família carrega a responsabilidade de respeitar e cuidar da natureza.

A natureza também nos orienta através dos cantos dos pássaros, e através de sinais do céu, dos trovões. Um sinal que vou registrar aqui é que guando a gente vê no céu estrelas juntas perto da lua nova é porque vai ter casamento, e isso vem de geração e geração. Esses conhecimentos nos repassamos para a criança perto do fogo na hora do tereré e no momento de visitas aos parentes. 
Essa responsabilidade até as crianças carrega dentro de si, e isso ajuda não somente o seres humanos, mas sim todo o mundo, conforme os rezadores e as rezadoras dizem, o mundo, a água, a terra, o vento e o ar, está tudo ligado. O rezador/xamã senhor Cantalicio Godoi fala como o mar respira, o mar também respira como a gente, e a gente precisa de ar puro e limpo, o rezador/xamã Cantalicio fala que é pelas nascentes que o mar respira. Muitas pessoas vê uma nascente pensando que não serve pra nada, e que está ali atoa, e suja e destrói, mas toda essa ação humana vai prejudicando a respiração do mar, pois o mar também ajuda o mundo ficar equilibrado.

O rezador/xamã Cantalicio também nos diz sobre o alicerce do mundo hoje, que no início havia quatro alicerces grandes e muito seguros, e hoje por falta de cuidados e respeito a natureza, nós estamos correndo grande perigo, pois um alicerce caiu e o outro está começando a pegar cupim, isso esta acontecendo, e nós Guarani Ñandeva precisamos unir nossas rezas e ouvir outras rezas, pois nós os Guarani temos os guardiões das nossas rezas, e guando rezamos eles os guardiões ouvem e chegam junto com os trovões e os relâmpagos para ver a situação da terra e do seres humanos.

A relação com a natureza, os Guarani de acordo o Ñaderuete Tupã falou para o rezadores que nós fomos batizados junto com a natureza e por isso a nossa cultura se completa com a natureza, a gente se comunica através dos cantos de pássaros, através dos trovões, temos reza para acalmar o vento forte, temos remédios para curar picada de cobra, reza para acalmar animais feroz. São técnicas nossas, técnicas Guarani, no mato existe toda essa forma de viver, conforme o plano de Deus é criação divina, nós não nos sentimos inferior e nem superior as outras culturas.

Mas, na chegada dos povos da "cultura dominante" eles se perguntaram será que são humanos ou animais. Disseram desde a primeira conquista, e então começa a expansão econômica e o avanço do latifúndio. Desde então há comentários sobre a técnica menos avançadas e a técnica mais avançadas, mas a cultura não se reduz a técnica, sabemos o quão alto é o preço que a civilização ocidental paga pelo avanço tecnológico, em outro nível da cultura, principalmente na relação do homem com a natureza, nesse sentido os Guarani é um povo que ainda permite esperança para o mundo. 
Nesse contexto a criança participa de todo o aprendizado Guarani, assim é como as crianças descobrem os valores culturais de ser Guarani, descobri a origem do seu nome, como ele aceitou a cultura, tudo isso é uma nova aliança cultural onde a criança vive no passado, no presente e com certeza no futuro.

\section{Sobre o autor:}

Eliezer Martins Rodrigues: Mestre em Educação pela Universidade Católica Dom Bosco (UCDB). Cientista Social pela Universidade Federal da Grande Dourados (UFGD). Coordenador e professor na Secretaria Municipal de Educação de Japorã, Mato Grosso do Sul (MS). E-mail: eliezer2016martins@gmail.com, ORCID: http://orcid.org/0000-0003-2215-3713

Recebido em: 07/09/2020

Aprovado para publicação: 11/09/2020 